\title{
Case study of the mesospheric and lower thermospheric effects of solar X-ray flares: coupled ion-neutral modelling and comparison with EISCAT and riometer measurements
}

\author{
C.-F. Enell ${ }^{1}$, P. T. Verronen ${ }^{2}$, M. J. Beharrell ${ }^{3}$, J. P. Vierinen ${ }^{1}$, A. Kero ${ }^{1}$, A. Seppälä ${ }^{2}$, F. Honary ${ }^{3}$, T. Ulich ${ }^{1}$, and \\ E. Turunen ${ }^{1}$ \\ ${ }^{1}$ Sodankylä Geophysical Observatory, University of Oulu, Sodankylä, Finland \\ ${ }^{2}$ Earth Observation unit, Finnish Meteorological Institute, Helsinki, Finland \\ ${ }^{3}$ Dept. of Communication Systems, Lancaster University, UK
}

Received: 20 December 2007 - Revised: 16 June 2008 - Accepted: 16 June 2008 - Published: 5 August 2008

\begin{abstract}
Two case studies of upper mesospheric and lower thermospheric (UMLT) high-latitude effects of solar X-ray flares are presented. Sodankylä Ion-neutral Chemistry Model (SIC) electron density profiles agree with D-region EISCAT and riometer observations, provided that the profiles of the most variable ionisable component, nitric oxide, are adjusted to compensate for $\mathrm{NO}_{\mathrm{x}}$ production during preceding geomagnetically active periods. For the M6-class flare of 27 April 2006, following a quiet period, the agreement with cosmic noise absorption observed by the Sodankylä riometers was within reasonable limits without adjustment of the [NO] profile. For the major (X17-class) event of 28 October 2003, following high auroral activity and solar proton events, the NO concentration had to be increased up to on the order of $10^{8} \mathrm{~cm}^{-3}$ at the D-region minimum. Thus [NO] can in principle be measured by combining SIC with observations, if the solar spectral irradiance and particle precipitation are adequately known.
\end{abstract}

As the two case events were short and modelled for high latitudes, the resulting neutral chemical changes are insignificant. However, changes in the model ion chemistry occur, including enhancements of water cluster ions.

Keywords. Atmospheric composition and structure (Ion chemistry of the atmosphere) - Ionosphere (Ion chemistry and composition; Solar radiation and cosmic ray effects)

Correspondence to: C.-F. Enell

(carl-fredrik.enell@sgo.fi)

\section{Introduction}

$\mathrm{X}$-rays are emitted by the hot solar corona and absorbed in the upper and middle atmosphere through direct ionisation followed by indirect ionisation by the emitted energetic secondary photoelectrons. The variability of solar emission in this short-wavelength regime is very large. Figures 2 and 8 show measurements of hard X-rays, defined here as electromagnetic radiation of wavelengths shorter than $1 \mathrm{~nm}$, from the GOES Space Environment Monitor X-ray (SEM XRS) sensors (Sylwester et al., 1995). It is evident that the irradiance can vary by 5 orders of magnitude or more. The upper-atmospheric effects of X-ray absorption during solar flares have been studied by satellites such as TIMED (Woods et al., 2002) and the Student Nitric Oxide Explorer (SNOE), (Bailey et al., 2000). The effects can also readily be monitored remotely by ground-based instruments. During flare events the electron density in the upper mesosphere - lower thermosphere (UMLT) region is enhanced, which affects the propagation of radio waves as measured in HF cosmic noise absorption with riometers as well as with monitoring of VLF transmitters. Based on VLF and riometer measurements, Thomson et al. (2004) and Brodrick et al. (2005) studied the major solar flare of 4 November 2003, which saturated the GOES detectors. These studies independently concluded that the X-ray flare magnitude was in the range $\mathrm{X} 40-\mathrm{X} 45$, i. e., the irradiance was $4.0-4.5 \times 10^{-3} \mathrm{~W} \mathrm{~m}^{-2}$ in the wavelength range $0.1-0.8 \mathrm{~nm}$ at $1 \mathrm{AU}$.

The ion and neutral chemical effects of two X-ray flares have here been modelled for the high latitudes of the EISCAT radar site near Troms $\varnothing$, Norway $\left(69.59^{\circ} \mathrm{N}, 19.23^{\circ} \mathrm{E}\right)$

Published by Copernicus Publications on behalf of the European Geosciences Union. 


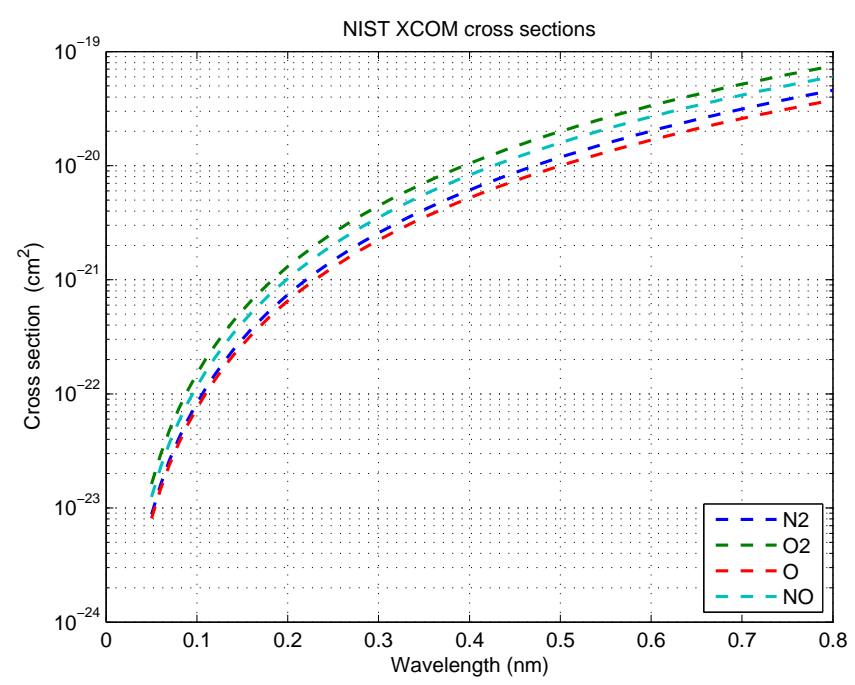

Fig. 1. The X-ray cross sections of the major atmospheric species, as taken from the NIST XCOM data base (Berger et al., 1998).

and the riometers at Sodankylä Geophysical Observatory, Finland $\left(67.37^{\circ} \mathrm{N}, 26.63^{\circ} \mathrm{E}\right)$, respectively. The first event, on 28 October 2003, was a large solar flare preceding the socalled "Halloween storm". Several solar proton events also occurred during this period (Verronen et al., 2005). The flare magnitude was classified as X17 (maximum irradiance in the wide-band GOES XRS detector $17 \times 10^{-4} \mathrm{~W} \mathrm{~m}^{-2}$ ). During this flare event the EISCAT VHF radar ran the arc_dlayer experiment as a UP (Unusual Programme) special event.

The second event is the M6 (maximum irradiance $6 \times 10^{-5} \mathrm{~W} \mathrm{~m}^{-2}$ ) flare that occurred during the local afternoon and evening of 27 April 2006. The latter case is suitable for comparison and verification especially since the GOES detectors were neither saturated nor much affected by particles, which may be the case during X-class events.

The rates of hard X-ray ionisation were calculated by fitting a spectral shape to the two GOES hard X-ray channels and integrating those over the cross sections of primary ionisation. Secondary ionisation by the X-ray photoelectrons was parameterised. The resulting ionisation rates were imposed on the comprehensive Sodankylä Ion-neutral Chemistry (SIC) model. As will be shown, the resulting electron density profiles can be forced into agreement EISCAT observations by adjusting the initial concentration of nitric oxide (NO). For the quiet period of April 2006, the modelled and observed cosmic noise absorptions agree rather well without any adjustments of background [NO].

\section{SIC modelling}

In the modelling of the effects of these two events we have applied version 6.8.1 of the SIC model. This model includes over 300 reactions of
- 36 positive ions

- 27 negative ions

- 14 neutrals

and is the result of the extensions of the original Sodankylä Ion Chemistry model (Turunen et al., 1996) as described by Verronen (2006). The model uses altitude profiles of temperature and major atmospheric species from the empirical MSISE-90 model (Hedin, 1991) and from Shimazaki (1984). Photoionisation of molecular and atomic oxygen as well as dissociation of the molecular major species are calculated based on solar spectral irradiances from the Solar2000 model (Tobiska et al., 2000). The radiative transfer calculation follows Rees (1989) with numerical integration based on Press et al. (1992), disregarding refraction for all wavelengths.

The spectral region was extended into the hard X-ray region, $0.1-1 \mathrm{~nm}$, by including ionisation and dissociation cross sections of $\mathrm{N}_{2}, \mathrm{O}_{2}, \mathrm{NO}$ and $\mathrm{O}$ (Fig. 1) from the NIST XCOM database (Berger et al., 1998). For solar hard Xray spectra, many empirical models are nowadays becoming available, such as the Solar Irradiance Platform that is to replace the current Solar2000 (Tobiska et al., 2000) model. For the present purpose, however, we used a simple analytical approximation (Sect. 3). This procedure will be shown to yield results in approximate agreement with observations for the M-class flare. However, the possible choices of spectral models will affect the results and interpretation with respect to the adaptation of [NO] profiles, so a proper representation of the solar spectrum is an important issue for further studies.

From the SIC model results, altitude profiles of electron density are calculated as

$N_{\mathrm{e}}(h)=\sum_{i=1}^{36}\left[P_{i}(h)\right]-\sum_{j=1}^{27}\left[N_{j}(h)\right]$

where the sums represent the total concentrations of the positive and negative ions, respectively.

When setting up a new run, the SIC model is initialised by repeating a diurnal cycle with photochemical forcing only until a quasi-steady cycle is obtained. This method provides control (background) profiles for comparison of the results as well as initial concentration profiles of all modelled species for the event runs.

\section{Scaling of GOES data}

The SEM XRS system of each GOES satellite consists of two ionisation chambers, one of which is filled with argon and covers the nominal wavelength range of $0.1-0.8 \mathrm{~nm}$, the other one xenon-filled and covering the short-wavelength range of $0.05-0.4 \mathrm{~nm}$ (see Garcia, 1994). To convert the fluxes integrated over these channels into spectral irradiances 
for the modelling, we have applied an empirical spectrum according to Culhane and Acton (1970); in photon energy $E$ (keV) scale

$N(E)=C \cdot T^{-0.2} E^{-1.3} \exp \left[-\frac{E}{k T}\right]\left[1-\left(\frac{E}{88.0}\right)^{0.33 k T}\right]^{-1}$

Equation (2) contains two free parameters, a solar coronal plasma temperature $T$ and a constant $C$ representing a lineof-sight integral of coronal electron density. $k$ is Boltzmann's constant. It can thus be numerically fitted to reproduce the two measurement channels of GOES. For the high X-ray irradiances of 28 October 2003, Eq. (2) does not hold true, since it is valid for $T<20 \times 10^{6} \mathrm{~K}$ only. The wide X-ray channel was also saturated during the maximum. In these cases the spectrum for $T=20 \times 10^{6} \mathrm{~K}$ was shifted towards smaller wavelengths until the GOES channel ratios matched and then $C$ was scaled to reproduce the irradiance(s) of the non-saturated channel(s).

For the 27 April 2006 case the maximal irradiances observed were lower than the minimal irradiances of the 28 October 2003 event, so Eq. (2) is assumed to be applicable throughout the event. The scaling for this event could therefore be automated and for simplicity we assumed the spectral responses of the two ionisation chambers to be Gaussian with half-widths of $0.1-0.8 \mathrm{~nm}$ and $0.05-0.3 \mathrm{~nm}$, respectively, the latter because the $\mathrm{X}$-ray ionisation chamber has a rather sharp cutoff at $0.3 \mathrm{~nm}$. Although the fitting procedures described here are somewhat arbitrary, the spectra obtained have proven to yield results (electron density profiles) well in agreement with observations.

\section{Case 1: 28 October 2003}

\subsection{Data analysis}

The left plot of Fig. 2 shows the two 5-min integrated GOES10 SEM X-ray channels for the time of the event. The maximum occurred close to local noon. However, in late October the solar elevation is low also at noon - the solar zenith angle used in the calculation was close to $83^{\circ}$ throughout the event. During the event the EISCAT VHF radar was running the high-resolution arc_dlayer experiment which is a pulse-to-pulse long-lag experiment with high time resolution for the ranges $60-140 \mathrm{~km}$.

For analysing the experiment data, the Fukuyama and Kofman (1980) (henceforth F-K) theory was fitted to the EISCAT autocorrelation function (ACF) profiles using the Metropolis-Hastings Markov Chain Monte Carlo (MCMC) method (Hastings, 1970). MCMC is a random sampling procedure which automatically yields the posteriori distributions of the free parameters. The F-K fit parameters are electron density $N_{\mathrm{e}}$, electron temperature, ion velocity, ratio $\lambda=N_{-} / N_{\mathrm{e}}$ of negative ion to electron density, and collision frequency $v_{\text {in }}$. Since the MCMC method can, by definition, yield only results within the given a priori distributions of the parameters to fit, wide step-function type prior distributions were used. The calibration factor of the ACF profiles was estimated by fitting the first lags of the ACFs to the so-called raw $N_{\mathrm{e}}\left(N_{\mathrm{e}}^{*}\right)$ profiles given by the standard EISCAT analysis software GUISDAP ${ }^{1}$ in the E region. Since ISRs do not measure the true raw backscattered power (zero lags of the ACF), GUISDAP calculates the $N_{\mathrm{e}}^{*}$ values from the $32-\mu \mathrm{s}$ pseudo-zero lags of the arc_dlayer experiment, automatically calibrating against the $f o E$ of the co-located EISCAT dynasonde (I. Häggström and M. Rietveld, personal communication).

\subsection{Modelling}

For modelling the 28 October 2003 case, the SIC model was initialised for the location of EISCAT at Ramfjordmoen near Troms $\varnothing$, Norway $\left(69.59^{\circ} \mathrm{N}, 19.23^{\circ} \mathrm{E}\right)$. The MSIS background atmosphere was calculated with the following parameters: $F_{10.7}=217.8$ (solar $10.7 \mathrm{~cm}$ flux of the preceding day), $F_{10.7 \mathrm{~A}}=164.56$ (3-month average of $F_{10.7}$ ) and daily average $A_{\mathrm{p}}=22$. Calculations of ionisation and dissociation of nitrogen and oxygen were included as in the standard SIC 6.8.1 model and in addition rates due to the fitted hard X-ray spectra, of which the right plot of Fig. 2 shows two examples, were included. The radiative transfer calculations were updated with 5-min time resolution together with estimates of vertical transport, etc., as described in Verronen (2006).

\subsubsection{Scaling of nitric oxide}

Nitric oxide (NO) is the main varying ionisable species in the altitude range of this study. During quiet times, solar Lyman- $\alpha$ ionisation of NO is the main source of the lower ionosphere. Hard X-rays, as well as auroral electrons and solar protons, efficiently ionise also the main constituents of the atmosphere, but we assume their concentrations to be constant, given by the MSISE-90 background.

The odd nitrogen family $\left(\mathrm{NO}_{\mathrm{x}}=\mathrm{N}+\mathrm{NO}+\mathrm{NO}_{2}\right)$ is longlived, the lifetime being from about one day in the solarilluminated upper atmosphere up to months in the polar night. Under such conditions transport of $\mathrm{NO}_{\mathrm{x}}$ to lower altitudes and latitudes is important (Siskind et al., 1997; Callis and Lambeth, 1998; Vitt et al., 2000; Seppälä et al., 2007). The balance between the species is governed by photochemistry, so that most $\mathrm{NO}_{\mathrm{x}}$ is converted into NO during daytime. The concentration of NO thus depends on transport and preceding production by auroral activity and proton events. [NO] has a maximum at altitudes between 100 and $120 \mathrm{~km}$, where both soft X-ray radiation (1-7 nm) and auroral electron precipitation (assuming typical characteristic energies of $1-10 \mathrm{keV}$ ) dissipate most of their energy. As shown by SNOE the concentration of NO around the $110-\mathrm{km}$ peak varies between $10^{7}$ and $10^{9} \mathrm{~cm}^{-3}$ at high latitudes. See the

\footnotetext{
${ }^{1}$ see the EISCAT homepage http://www.eiscat.se
} 

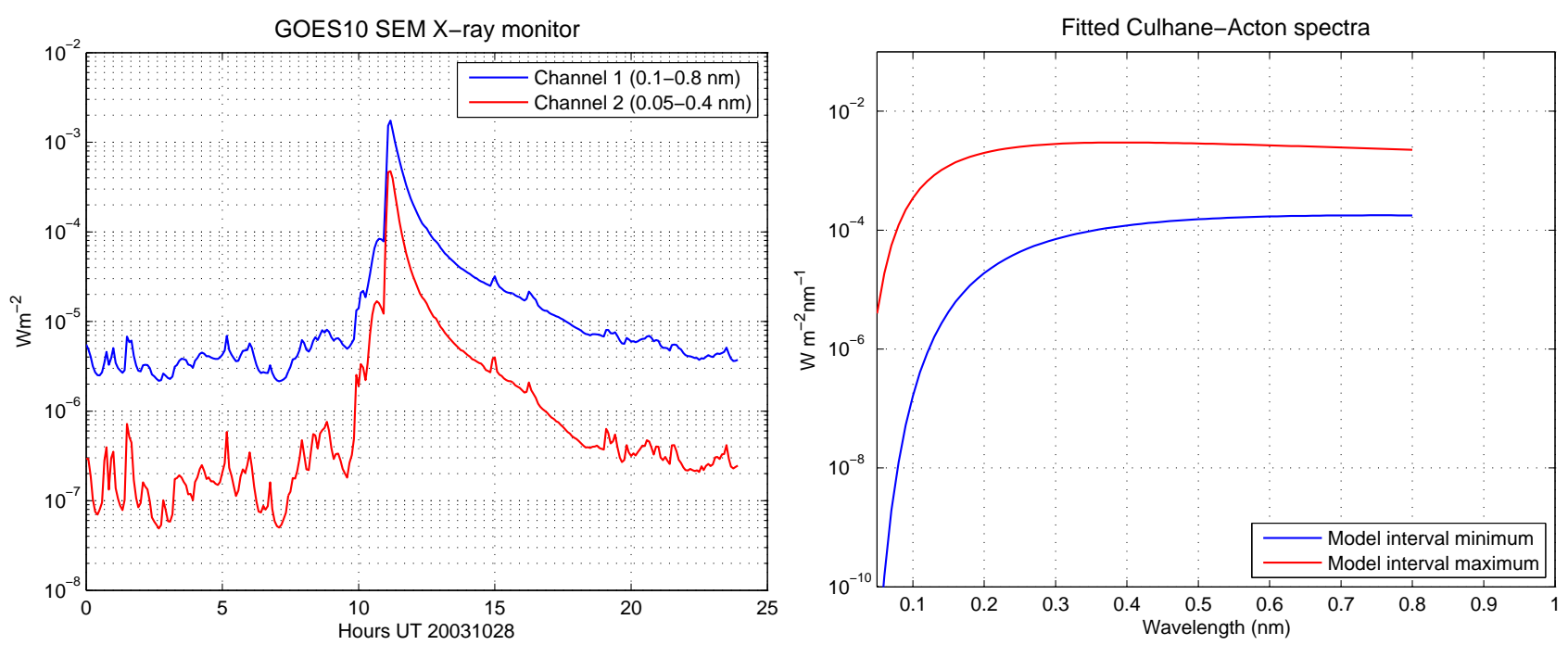

Fig. 2. Left plot: The GOES X-ray channels for the 28 October 2003 event. It should be noted that the wider channel saturated during the maximum. Right plot: Fitted spectra for the maximum (around 11:10 UT) and minimum (X-rays switched on at 10:50 UT) fluxes during the model run. Similar spectra fitted to 5-min average GOES data were used throughout the flare runs. The solar zenith angle was around $83^{\circ}$ throughout the event, since it occurred close to local noon. See Sect. 3 for details.



Fig. 3. SIC model NO concentration profiles at the onset of the X17 flare of 28 October 2003, 10:45 UT. The initial profile was scaled by constant factors of 10, 30 and 100 at start of run (08:00 UT); thereafter the profiles change slowly by chemical reactions.

studies by Barth (1992, 1996); Siskind et al. (1998); Saetre et al. (2004) and Saetre et al. (2007) for further discussions of these measurements and modelling of NO. We can thus expect a concentration on the order of $10^{9} \mathrm{~cm}^{-3}$ in active periods.

To account for this variability of [NO], the modelled and measured $N_{\mathrm{e}}$ profiles were brought into agreement by scal- ing the SIC initial concentrations of nitric oxide at the start of the model run (08:00 UT), multiplying by 10,30 and 100 . The model runs were continued without X-ray ionisation until 10:45 UT, allowing the numerical solutions to settle to NO concentrations acceptably close to the observed range at the maximum. The resulting NO concentration profiles at 10:45 UT are shown in Fig. 3. X-ray ionisation was switched on at 10:50 UT.

The left plot of Fig. 4 shows SIC modelled and arc_dlayer fitted electron densities for 09:45 UT, which was the time of a minimum in the electron density before the flare peak. The F-K MCMC fit was done on data averaged over 09:25-09:45 UT. For the GUISDAP results the medians of the 1-min profiles in the same time interval is used, bad profiles removed by manual inspection. Likewise, the left plot of Fig. 5 shows modelled and measured profiles for the peak, 11:10 UT. The EISCAT results were here averaged over 11:05-11:20 UT. The right plots show the relative difference between the F-K MCMC fitted and the SIC model electron density profiles, $\left(N_{\mathrm{e}}(\mathrm{F}-\mathrm{K})-N_{\mathrm{e}}(\mathrm{SIC})\right) / N_{\mathrm{e}}(\mathrm{F}-\mathrm{K})$, at the $1 \mathrm{~km}$ resolution of the SIC model runs.

The agreement between SIC modelled and EISCAT arc_dlayer fitted electron density clearly falls into three regions.

1. $75-100 \mathrm{~km}$ : The profiles agree well when starting with $30-100$ times the SIC quiet background [NO]. This is not unreasonable since proton events occurred and auroral activity was very high during the days preceding the event and the following extreme "Halloween storm". We have previously modelled the effects of 

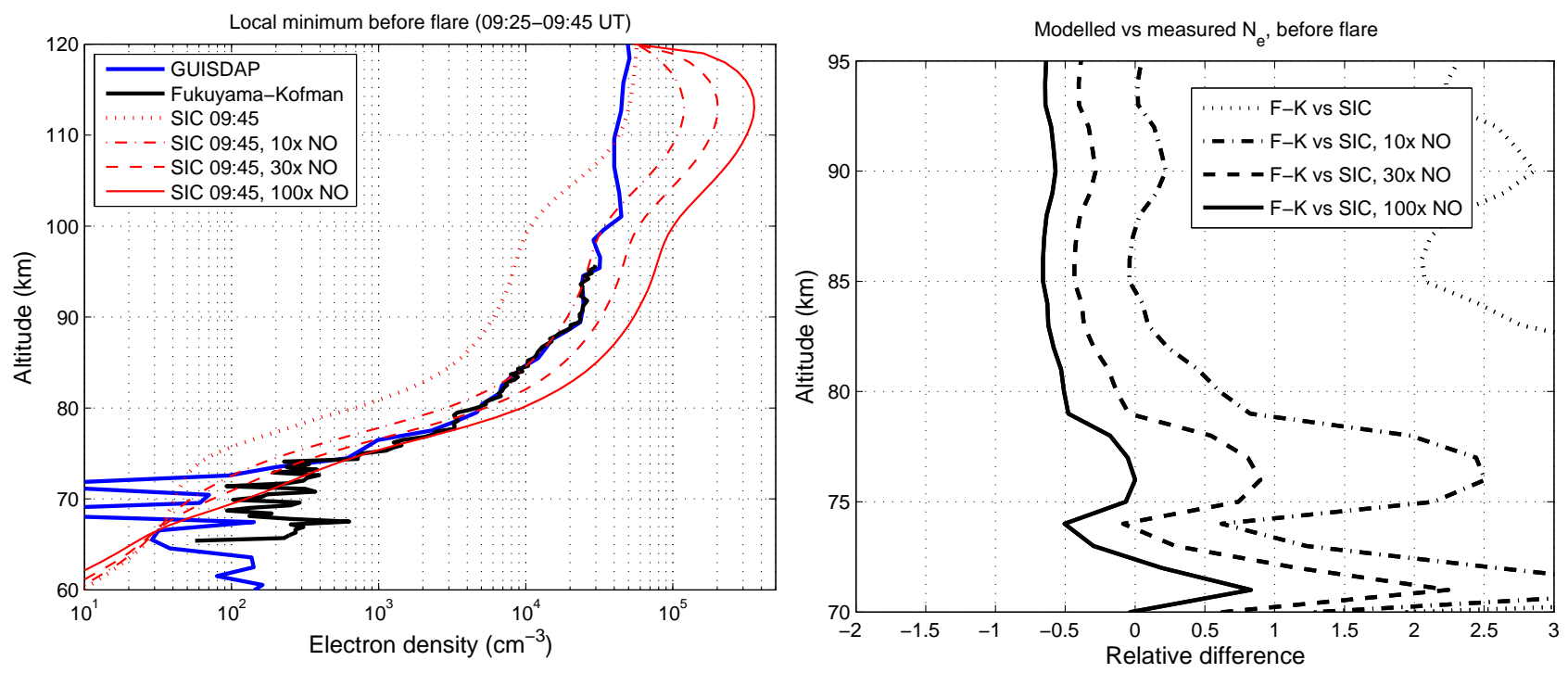

Fig. 4. The 28 October 2003 X17 flare event. Left plot: SIC and EISCAT results before the flare onset. GUISDAP profiles are averaged over the minimum in electron density preceding the flare, 09:25-09:45 UT, bad profiles removed. The F-K MCMC fit was applied to data averaged over the same interval. SIC was run without hard-X-ray ionisation, the initial [NO] profile multiplied by 10, 30 and 100 at 08:00 UT. The SIC results are shown for 09:45. Right plot (N.B: altitudes restricted to 70-95 km): Relative differences between F-K MCMC and SIC electron densities, $\left(N_{\mathrm{e}}(\mathrm{F}-\mathrm{K})-N_{\mathrm{e}}(\mathrm{SIC})\right) / N_{\mathrm{e}}(\mathrm{F}-\mathrm{K})$.

solar protons alone during this period (Verronen et al., 2005). On 28 October 2003, SIC modelled [NO] in this altitude range was $10^{7}-10^{8} \mathrm{~cm}^{-3}$, increasing even more after the following "Halloween" events. Taking also auroral electrons into account, a concentration of close to $10^{9} \mathrm{~cm}^{-3}$ as in these cases (Fig. 3) is therefore not unrealistic. The exact shape of the modelled electron density profiles will depend not only on [NO] and the applied hard X-ray spectra but also on EUV, soft X-rays and particle precipitation. However, at the time of onset of this event it appears that simultaneous particle precipitation can be neglected.

2. Above $100 \mathrm{~km}$ : Before the flare onset (Fig. 4) the electron density is highly overestimated for the [NO] scaling required for best agreement at $75-100 \mathrm{~km}$. As seen in Fig. 3 the model concentration of NO at the maximum near $110 \mathrm{~km}$ is close to $10^{9} \mathrm{~cm}^{-3}$ or higher for all three scaling factors, so this scaling is possibly unrealistic. In that case, interpolation between the profiles can in principle be applied to obtain an estimate of the actual NO concentrations. However, part of the discrepancy, especially before the flare onset, can also be caused by the simple radiative transfer calculation overestimating soft X-rays and EUV at these altitudes for the high solar zenith angle of the event. This source of uncertainty should be eliminated by a proper radiative transfer calculation, but this is beyond the scope of the present study. More likely ionisation by EUV and soft
$\mathrm{X}$-rays are underestimated at the flare maximum. Soft $\mathrm{X}$-rays $(>1 \mathrm{~nm})$ and EUV are included as a daily average from the SOLAR2000 model (Tobiska et al., 2000). Thus ionisation by soft X-rays and EUV in the model run does not follow the flare development. In this case the lower concentrations of Fig. 3 are still correct.

3. Below $75 \mathrm{~km}$ : The scattering is affected by the high collision frequency, by the presence of negative ions, and possibly also by radar self-clutter (F-region backscatter from preceding pulses aliased into the lowest ranges). The latter is significant only below $65 \mathrm{~km}$ (I. Häggström, personal communication). The upper panel of Fig. 6 confirms that negative ions are significant below $70 \mathrm{~km}$. The middle plot shows modelled and $\mathrm{F}-\mathrm{K}$ fitted values of the negative ion to electron density ratio $\lambda$ for the flare maximum.

The GUISDAP and F-K electron density profiles agree fairly well in the pre-flare case, but at the flare maximum the difference is large. The discrepancy between F-K and raw $N_{\mathrm{e}}$ (the latter not shown in the figures) is small, however, and attributable to the negative ions. Turunen (1993) has shown that the Fukuyama and Kofman (1980) theory represents the effect of negative ions well. As Fig. 7 shows, the difference is likely caused by the fact that GUISDAP uses a fixed collision frequency profile whereas it is a fitted parameter in the F-K MCMC retrieval. It can be seen that the F-K fit reproduces the mesopause as a change in the gradient. The 

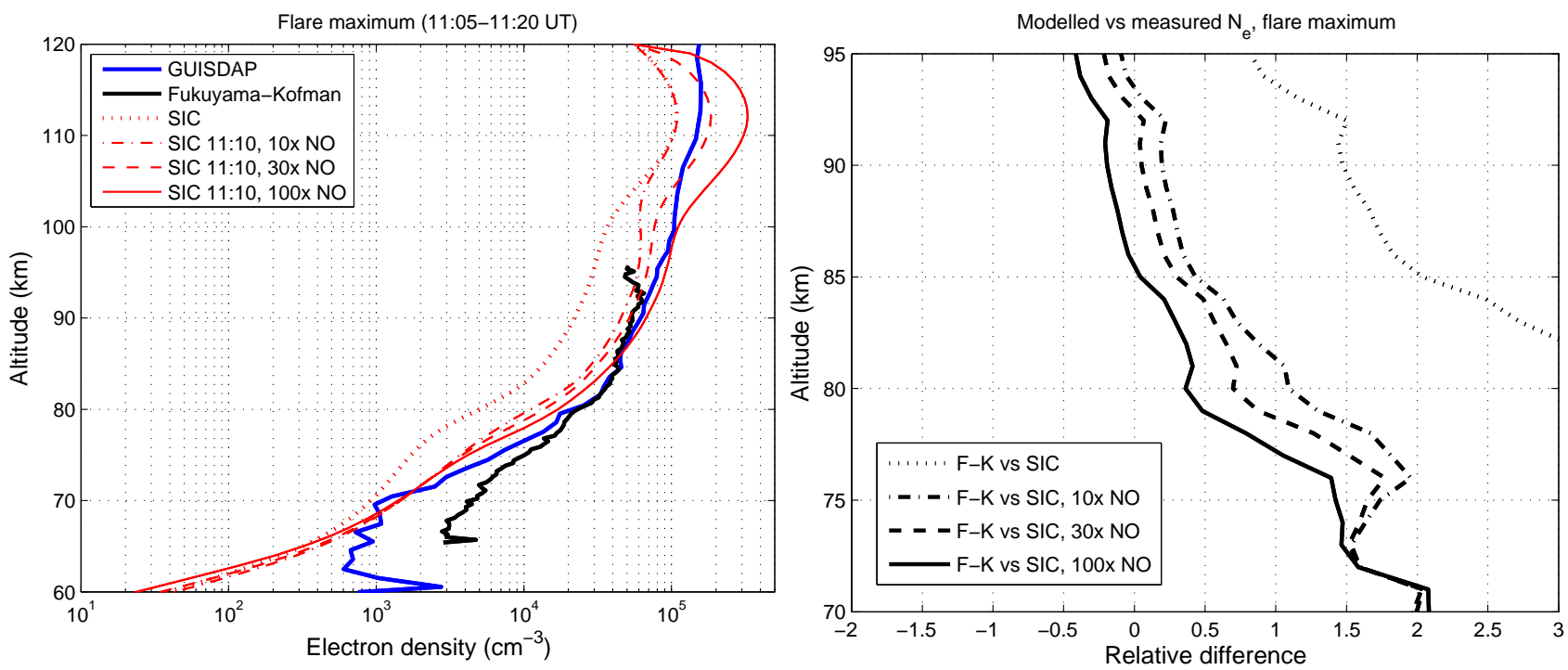

Fig. 5. The 28 October 2003 X17 flare event. Left plot: SIC and EISCAT results at the peak of the flare. GUISDAP profiles are averaged over the period 11:05-11:20 UT. The F-K MCMC fit was applied to data averaged over the same interval. In the model runs the hard X-rays based on the spectra fitted to GOES data were switched on at 10:50 UT. Results shown are for 11:10. Right plot (N.B: altitudes restricted to 70-95 km): Relative differences between F-K MCMC and SIC electron densities, $\left(N_{\mathrm{e}}(\mathrm{F}-\mathrm{K})-N_{\mathrm{e}}(\mathrm{SIC})\right) / N_{\mathrm{e}}(\mathrm{F}-\mathrm{K})$.

GUISDAP profile, calculated from the NRLMSISE-00 model (Picone et al., 2002) temperature and densities of $\mathrm{N}_{2}, \mathrm{O}_{2}$ and $\mathrm{O}$ only, clearly lacks this feature. Thus, the actual electron density at the flare peak is not well reproduced by the model - the difference is at least a factor of two. Proton precipitation probably began around this time (see Verronen et al., 2005), and the shortwavelength region of the Culhane and Acton (1970) spectrum (Eq. 2) may not be a good representation of the actual solar spectrum, especially since one of the GOES detectors was saturated and the spectrum was adapted manually. The discrepancy may also be an indication that it would be necessary to introduce hard-Xray ionisation earlier in the model run.

A narrow polar mesospheric winter echo (PMWE) is also visible at around $60 \mathrm{~km}$. The strength of the PMWE appears to follow the X-ray ionisation, which is expected since both ionisation and some perturbations, likely turbulence (Kero et al., $2008^{2}$ causing a density modulation fulfilling the Bragg condition at the radar wavelength are necessary for producing a strong echo.

The lower panel of Fig. 6 shows that the change in nitric oxide concentration due to the flare is completely negligible. The modelled relative change is less than $1 / 1000$, whereas the SIC model initialisation is considered conver-

\footnotetext{
${ }^{2}$ Kero, A., Enell, C.-F., Kavanagh, A., Vierinen, J., Virtanen, I., and Turunen, E.: Could negative ion production explain the Polar Mesosphere Winter Echo (PMWE) modulation in active HF heating experiments?, Geophys. Res. Lett., in preparation, 2008.
}

gent for changes of less than a few per cent per cycle. This does not mean that flares are not a possible significant source of atmospheric NO. Solar flare events affect the entire sunlit atmosphere and may last for several days. At lower latitudes, where the background concentration is orders of magnitude smaller due to transport and the absence of particle precipitation, flares are likely to enhance [NO] significantly. Refer to the SNOE observations, such as Barth $(1992,1996)$; Barth and Bailey (2004) and Siskind et al. (1998).

\section{Case 2: 27 April 2006}

The event of 27 April 2006 represents an M-class flare (M6) in a less disturbed period near solar minimum. The maximum occurred in the local afternoon and evening, but since late April is close to the beginning of polar day the solar elevation was higher than during the 28 October 2003 X17 event. In the period 15:00-17:00 UT the solar zenith angle increased from $70^{\circ}$ to $82^{\circ}$. The EISCAT radars were not running during the maximum of this flare event, only in the morning and late evening, so comparison with modelling would not be straightforward. Therefore we restrict this study to a comparison with riometer measurements. Figure 8 shows the X-ray fluxes measured by the GOES 10 satellite during 27 April 2006. For these runs the SIC model was initialised for Sodankylä, Finland $\left(67.37^{\circ} \mathrm{N}, 26.63^{\circ} \mathrm{E}\right)$. For the MSISE-90 background model the parameters $F_{10.7}=96.3$, $F_{10.7 \mathrm{~A}}=79.7$ and $A_{\mathrm{p}}=3$ were used. The model was run for the time interval 14:00-18:00 UT with and without additional 

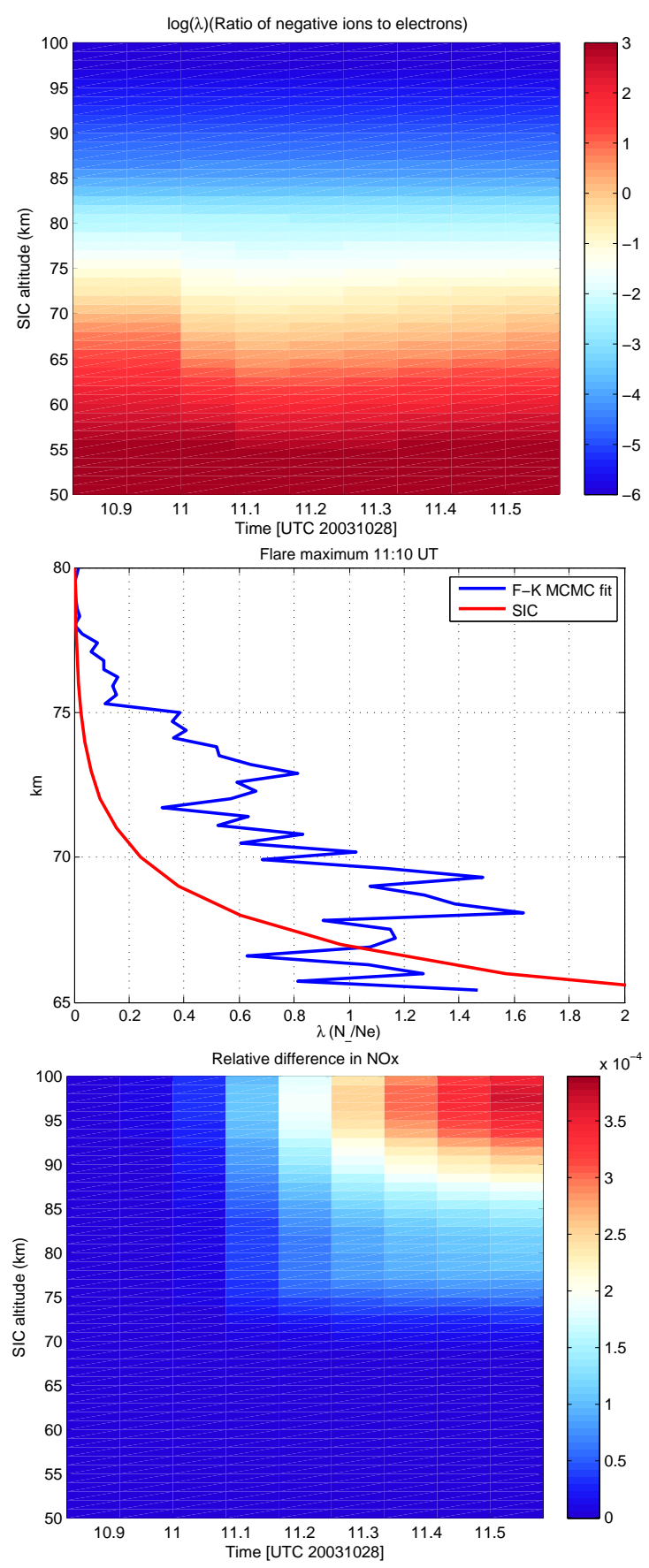

Fig. 6. Upper panel: SIC modelled ratio $\lambda$ of negative ion to electron density for the 28 October 2003 flare event. Runs start with 100 times the background run NO concentration at 08:00. Middle plot: SIC modelled and F-K MCMC fitted $\lambda$ for the 28 October 2003 flare maximum (11:10 UT). Lower panel: Relative $\mathrm{NO}_{\mathrm{x}}$ $\left(\mathrm{N}+\mathrm{NO}+\mathrm{NO}_{2}\right)$ enhancement due to the flare (event run vs control run for 100x background [NO] at 08:00 UT). Modelled enhancements of less than a few per cent are insignificant, so there is clearly no significant change here.

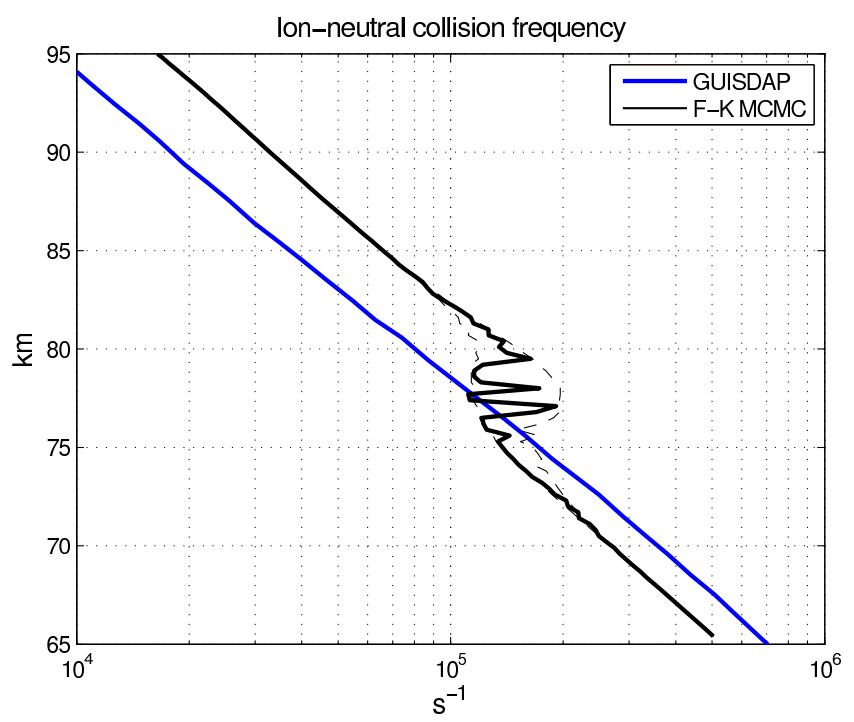

Fig. 7. Comparison of the fixed ion-neutral collision frequency profile of GUISDAP, calculated from MSIS $\mathrm{N}_{2}, \mathrm{O}_{2}$ and $\mathrm{O}$, and the Fukuyama-Kofman MCMC fit. The F-K fit reproduces the mesopause well whereas the exponential GUISDAP profile, likely differing from the real one, may cause misinterpretation of the electron densities.

$\mathrm{X}$-ray ionisation. In the EUV region of the solar spectra the irradiances were chosen as the maximum (per wavelength bin) of the Solar 2000 and the TIMED SEE (Woods et al., 2002) empirical spectral models. The EUV irradiances were seen to affect the results somewhat, again indicating that using proper solar spectra and radiative transfer calculations is important for the interpretation of the results. Updates of the $\mathrm{X}$-ray spectra and vertical transport were calculated for each minute and the MSIS background was updated for each 5min interval.

In the upper panel of Fig. 9 the development of the SIC calculated electron density during the event is presented. From the profiles of electron-neutral collision frequencies, given by an empirical function of temperature, $N_{\mathrm{e}}$ and the concentrations of $\mathrm{N}_{2}, \mathrm{O}_{2}, \mathrm{O}$ and $\mathrm{He}$ (Banks and Kockarts, 1973), the absorption of radio noise is calculated using the extended magneto-ionic theory of Sen and Wyller (1960), following Hultqvist (1968). A pure dipole approximation of the geomagnetic field at Sodankylä, magnetic latitude $63.8^{\circ} \mathrm{N}$, was adopted. Figure 10 shows the calculated and observed absorptions from the two Sodankylä riometers at 30 and $51.4 \mathrm{MHz}$. The modelled absorptions in $\mathrm{dB}$ were calculated for an isotropic wide-beam zenith geometry and therefore multiplied by a geometrical factor $G=1.2$.

The observed and modelled absorptions agree fairly well during the flare. The base level of the observation is higher than the modelled absorption due to the absorption at higher altitudes (see e.g. Ranta, 1979) not taken into account here. 

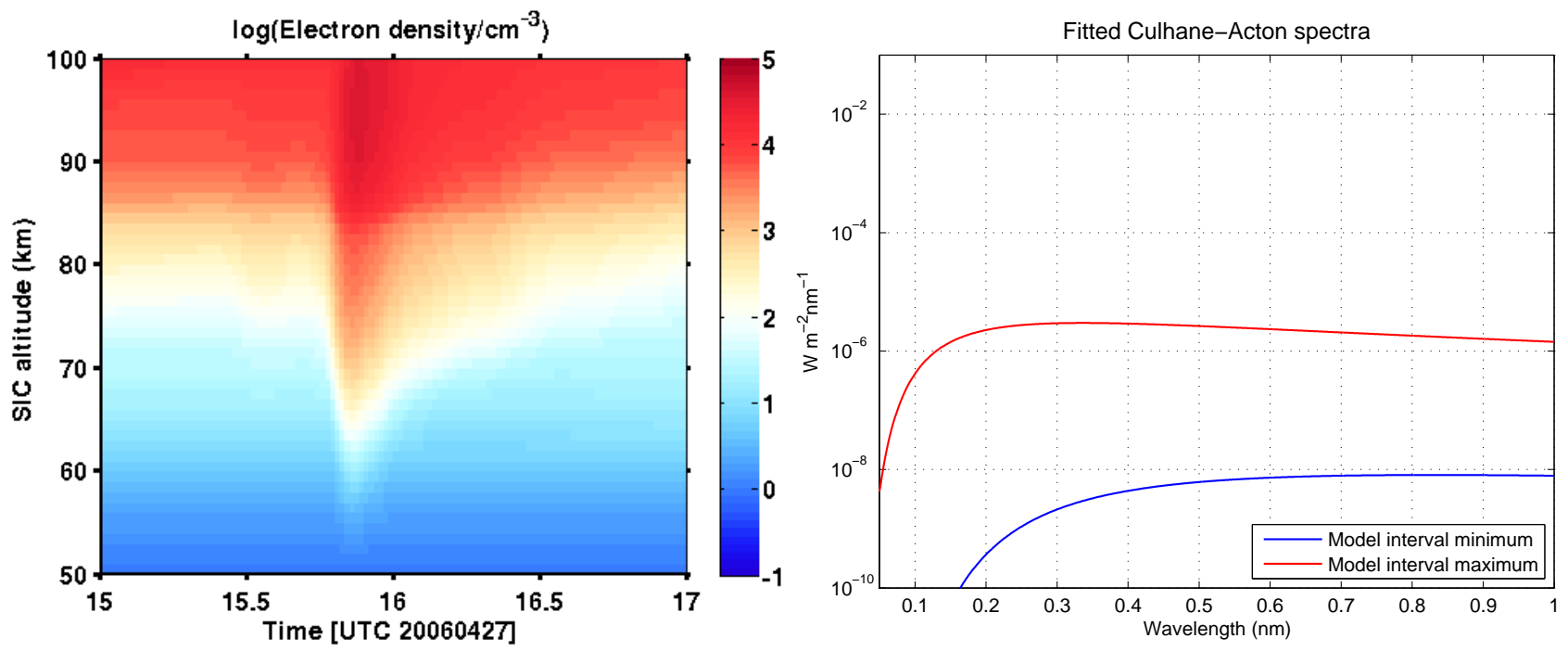

Fig. 8. GOES 10 measured X-ray irradiances for 27 April 2006. Left plot: The two GOES X-ray channels. Right plot: Fitted Culhane and Acton (1970) spectra for the maximum and minimum fluxes during the model run. Spectra fitted to 5-min average GOES data were used throughout the flare runs.

Neither did our modelling take into account D-region ionisation by electron precipitation. After approximately 17:00 UT (not shown here) the observed absorption increased above the modelled absorption. This was due to auroral activity as evident from inspection of magnetograms. Riometers showing an increase in cosmic noise absorption therefore cannot per se be used to distinguish between the effects of X-rays and precipitating particles. Direct or indirect measurements of particle precipitation is a necessary complement for interpreting the source of absorption enhancements.

The middle panel of Fig. 9 shows that the ratio of negative ions to free electrons reaches 0.1 at well below $80 \mathrm{~km}$ also in this case. The lower panel shows an example of water cluster ions (here a proton hydrate). It is seen that water cluster ion concentrations can increase by some orders of magnitude close to the mesopause. All excess ionisation, also by hard X-rays, could therefore play a role in the formation of aerosols in the mesopause region, affecting the occurrence of polar mesospheric summer echoes and noctilucent clouds during short-term events.

\section{Discussion}

The ion-neutral chemical model results of the 28 October 2003 X17 and 27 April 2006 M6 flares were compared with D-region radio observations. For the 27 April 2006 flare, the cosmic noise absorption calculated from SIC model $N_{\mathrm{e}}$ profiles agree at least qualitatively with riometer measurements without any adjustments. The background atmosphere as given by MSIS is likely more reliable for this latter case. MSIS interpolates profiles taking into account average $A_{\mathrm{p}}$ and $F_{10.7}$ above $100 \mathrm{~km}$. The solar elevation was also rather high during the onset of this event, so the calculation of photoionisation should work without major problems.

In the 28 October 2003 case, preceding auroral activity and proton precipitation have evidently enhanced the [NO] background in the upper mesosphere up to $10^{8}-10^{9} \mathrm{~cm}^{-3}$. As seen in Figs. 4 and 5 the pre-flare result above $110 \mathrm{~km}$ fits measurements without any scaling of the initial [NO] profile, whereas at the flare maximum the resulting electron density is too low. This is possibly due to underestimated soft X-ray fluxes. As mentioned, the issues of proper radiative transfer at high solar zenith angles also needs further investigation, since overestimates of the ionisation rates may instead follow and therefore the higher [NO] values may still be correct.

Neutral chemistry changes are insignificant in these shortlived high-latitude events, but further model studies will address the importance at low latitudes. Finally it should be noted that effect of heating on atmospheric dynamics during flares is also very likely of major importance, rendering the MSISE-90 model values unreliable, but this is beyond the scope of this paper. We plan to address these questions by applying a version of the CMAT2 three-dimensional model (Harris, 2001) where the radiative code has been extended into the hard-X-ray range (A. Dobbin and A. Aylward, personal communication).

\section{Conclusions}

The SIC model has been extended for modelling the effects of solar hard X-rays. The effects on ion chemistry are 


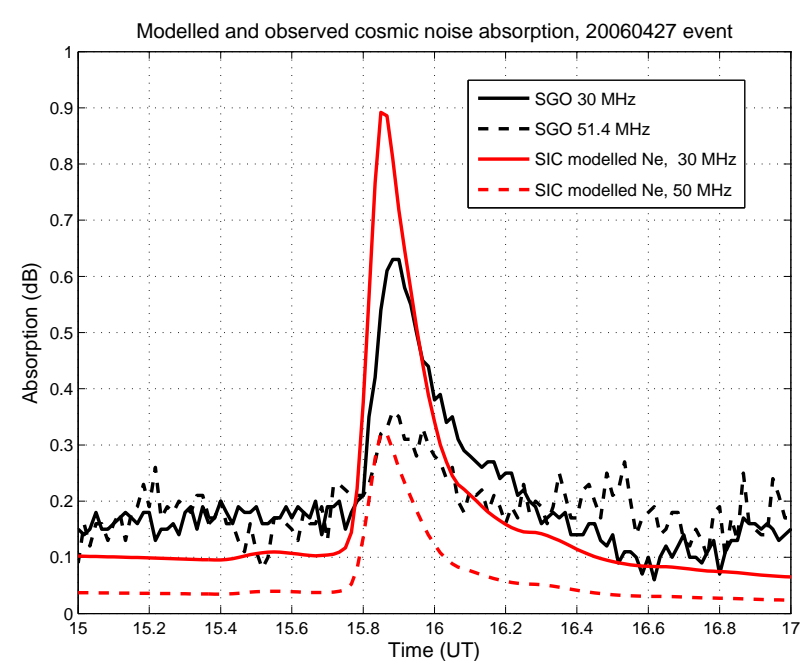

$\log (\lambda)$ (Ratio of negative ions to electrons)
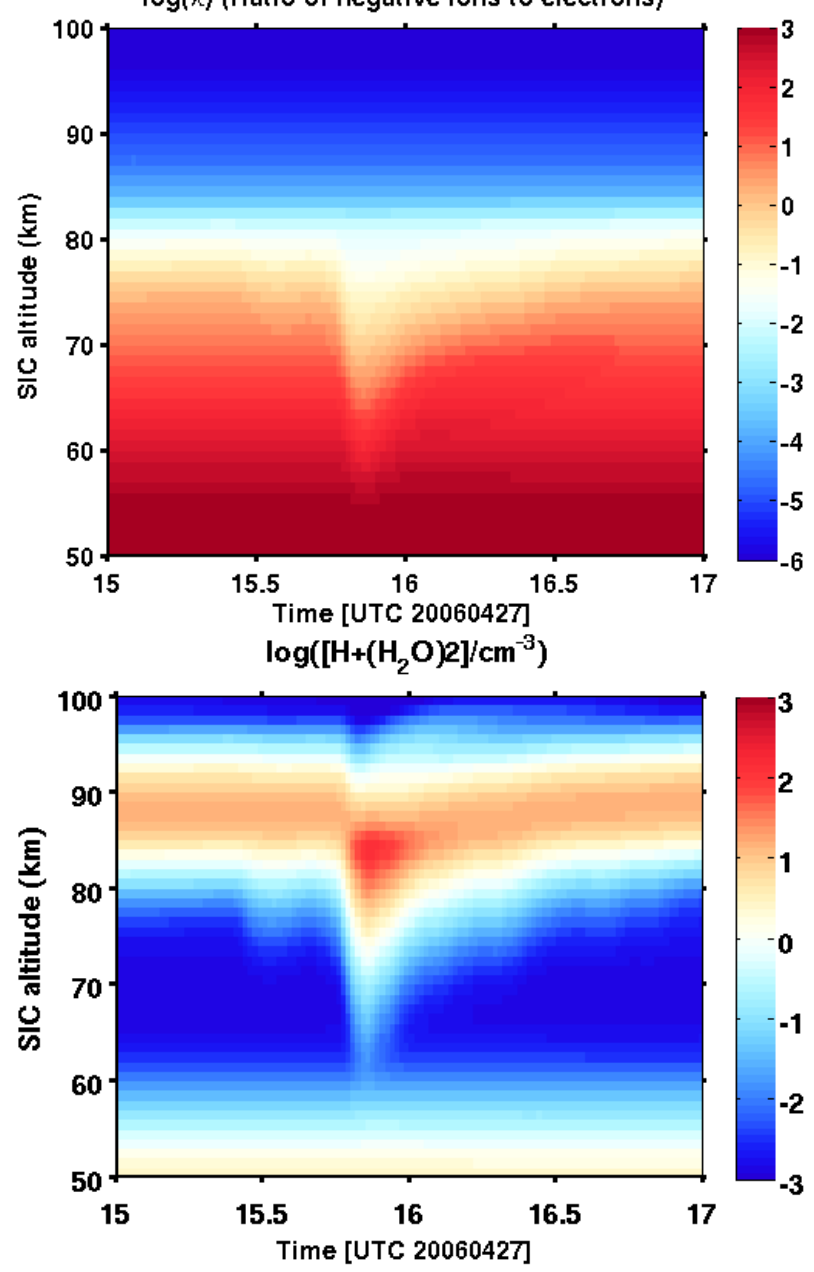

Fig. 9. SIC model results for the 27 April 2006 M6 flare event. Upper panel: Electron density. Middle panel: Ratio of negative ion to electron density. Lower panel: Concentration of the $n=2$ proton hydrate, showing an increase of a few orders of magnitude in the mesopause region.

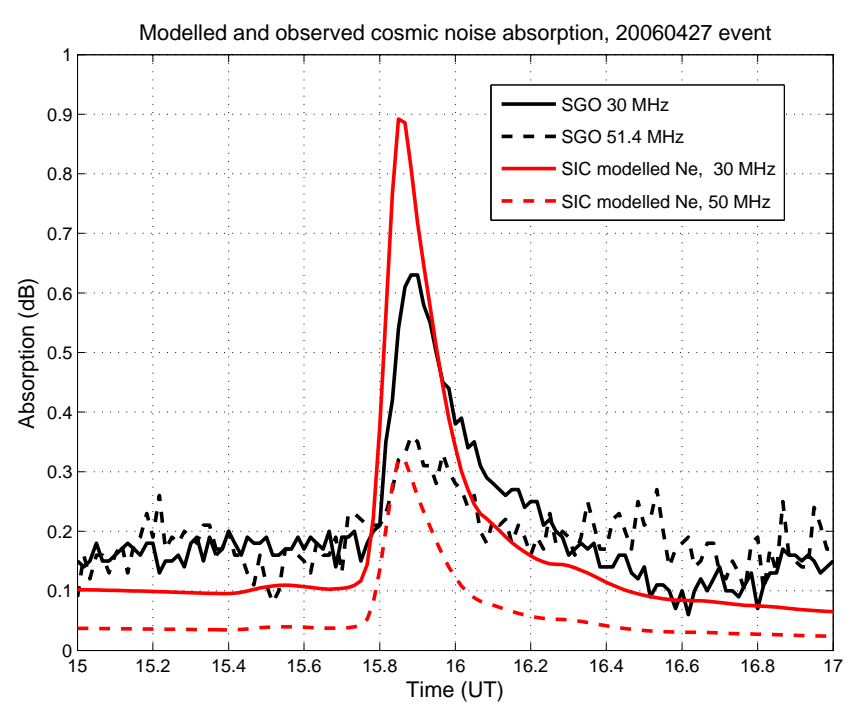

Fig. 10. Comparison of modelled and observed cosmic noise absorption for the 27 April 2006 M-class flare. Red curves: Absorption calculated from SIC modelled electron density profiles and MSISE-90 neutral density and temperature, using the Sen-Wyller formalism. Black curves: Absorption measured by the Sodankylä riometers at 30 and $51.4 \mathrm{MHz}$.

significant whereas neutral composition is little affected at the high latitudes and short time scales of this study.

As can be inferred especially from the case study of the October 2003 X17 flare, not only the [NO] profiles but also the applied approximations of the solar irradiance in the EUV and X-ray regions affect the measured electron density profiles. It would therefore be desirable to verify the proposed method by comparison with in-situ measurements of [NO] during flare events. The calibration of the electron density profiles and measured cosmic noise absorption is also important. Methods for obtaining accurate calibrations of EISCAT data even during times of strong ionisation, when ionosonde measurements of $f o E$ are impossible due to D-layer absorption and F-region clutter can affect the measurements, would be needed.

$\left[\mathrm{NO}_{\mathrm{x}}\right]$ and thus daytime $[\mathrm{NO}]$ is highly variable. At UMLT altitudes, where [NO] profiles normally have a minimum at $70-80 \mathrm{~km}$, preceding auroral activity and proton events may enhance [NO] by one to a few orders of magnitude. Such a scaling of [NO], i.e. total [NO] in the range $10^{8}-10^{9} \mathrm{~cm}^{-3}$, brings modelled and measured electron density profiles into agreement at these altitudes. We can therefore conclude with some confidence that the concentration was at least $10^{8} \mathrm{~cm}^{-3}$ there. Closer to the [NO] maximum around $110 \mathrm{~km}$ a smaller scaling factor must likely be used.

The combination of modelling based on measured or adequately parameterised solar spectra (and energies of precipitating particles) with incoherent scatter radar or riometer measurements thus provides a method for remote sensing 
of [NO] especially during geomagnetically active times, provided that the radiative transfer calculation and parameterisation of secondary ionisation are correct.

Acknowledgements. EISCAT is an international scientific association supported by the research councils of Finland (SA), France (CNRS), Germany (MPG), Japan (NIPR), Norway (RCN), Sweden (NFR) and the United Kingdom (STFC).

The main author is funded by the Academy of Finland through project 109054, Solar Energetic Radiation and Chemical Aeronomy of the Mesosphere. P. T. Verronen, A. Kero and A. Seppälä are partly funded by the Academy of Finland through project 123275, Thermosphere and Mesosphere affecting the Stratosphere.

The Solar2000 historical irradiances are provided courtesy of W. Kent Tobiska and Space Environment Technologies. These historical irradiances have been developed with partial funding from the NASA UARS, TIMED, and SOHO missions. Responsible for the TIMED SEE spectral model is Thomas Woods, LASP, University of Colorado. GOES data were obtained from the online database, http://goes.ngdc.noaa.gov/.

Topical Editor K. Kauristie thanks J. Stadsnes and another anonymous referee for their help in evaluating this paper.

\section{References}

Bailey, S. M., Woods, T. N., Barth, C. A., Solomon, S. C., Cranfield, L. R., and Korde, R.: Measurements of the solar soft X-ray irradiance by the Student Nitric Oxide Explorer: First analysis and underflight calibrations, J. Geophys. Res., 105, 27 179-27 193, 2000.

Banks, P. and Kockarts, G.: Aeronomy, Academic Press Inc., 1973.

Barth, C. A.: Nitric oxide in the lower thermosphere, Planet. Space Sci., 40, 315-336, 1992.

Barth, C. A.: Reference models for thermospheric nitric oxide, 1994, Adv. Space Res., 18, 179-208, 1996.

Barth, C. A. and Bailey, S. M.: Comparison of a Thermospheric Model with Student Nitric Oxide Explorer (SNOE) Observations of Nitric Oxide, J. Geophys. Res., 109, A03304, doi:10.1029/2003JA010227, 2004.

Berger, M. J., Seltzer, J. H. H. S. M., Chang, J., Coursey, J. S., Sukumar, R., and Zucker, D. S.: XCOM: Photon Cross Sections Database, http://physics.nist.gov/PhysRefData/Xcom/Text/ XCOM.html, copyright by the United States Secretary of Commerce, 1998.

Brodrick, D., Tingay, S., and Wieringa, M.: X-ray magnitude of the 4 November 2003 solar flare inferred from the ionospheric attenuation of the galactic radio background, J. Geophys. Res., 110, doi:10.1029/2004JA010960, 2005.

Callis, L. B. and Lambeth, J. D.: $\mathrm{NO}_{\mathrm{y}}$ formed by precipitating electron events in 1991 and 1992: Descent into the stratosphere as observed by ISAMS, Geophys. Res. Lett., 25, 1875-1878, 1998.

Culhane, J. L. and Acton, L. W.: A simplified thermal continuum function for the X-ray emission from coronal plasmas, Mon. Not. R. astr. Soc., 151, 141-147, 1970.

Fukuyama, K. and Kofman, W.: Incoherent scattering of an electromagnetic wave in the mesosphere: A theoretical consideration, J. Geomag. Geoelectr., 32, 67-81, 1980.
Garcia, H. A.: Temperature and emission measure from GOES soft X-ray measurements, Solar Phys., 154, 275-308, 1994.

Harris, M. J.: A New Coupled Middle Atmosphere and Thermosphere General Circulation Model: Studies of Dynamic, Energetic and Photochemical Coupling in the Middle and Upper Atmosphere, Ph.D. thesis, University College London, 2001.

Hastings, W. K.: Monte Carlo Sampling Methods Using Markov Chains and Their Applications, Biometrika, 57, 97-109, doi:10.2307/2334940, 1970.

Hedin, A. E.: Extension of the MSIS Thermospheric Model into the Middle and Lower Atmosphere, J. Geophys. Res., 96, 1159$1172,1991$.

Hultqvist, B.: On the solution of the integral equation relating height distribution of electron density to radio-wave absorption, Planet. Space Sci., 16, 529-537, 1968.

Picone, J. M., Hedin, A. E., Drob, D. P., and Aikin, A. C.: NRLMSISE-00 empirical model of the atmosphere: Statistical comparisons and scientific issues, J. Geophys. Res., A107, 1468, doi:10.1029/2002JA009430, 2002.

Press, W. H., Teukolsky, S. A., Vetterling, W. T., and Flannery, B. P.: Numerical Recipes in C, Cambridge University Press, second edn., 1992.

Ranta, H.: Riometer measurements of ionospheric absorption at high latitudes, Ph.D. thesis, Finnish Academy of Science and Letters, Sodankylä Geophysical Observatory, Sodankylä Geophysical Observatory Reports, 34, 1979.

Rees, M. H.: Physics and Chemistry of the Upper Atmosphere, Cambridge University Press, Cambridge, UK, 1989.

Saetre, C., Stadsnes, J., Nesse, H., Aksnes, A., Petrinec, S. M., Barth, C. A., Baker, D. N., Vondrak, R. R., and Østgaard, N.: Energetic electron precipitation and the NO abundance in the upper atmosphere: A direct comparison during a geomagnetic storm, J. Geophys. Res., 109, A09302, doi:10.1029/2004JA010485, 2004.

Saetre, C., Barth, C. A., Stadsnes, J., Østgaard, N., Bailey, S. M., Baker, D. N., Germany, G. A., and Gjerloev, J. W.: Thermospheric nitric oxide at higher latitudes: Model calculations with auroral energy input, J. Geophys. Res., 112, A08306, doi:10.1029/2006JA012203, 2007.

Sen, H. K. and Wyller, A. A.: On the Generalization of the Appleton-Hartree Magnetoionic Formulas, J. Geophys. Res., 65, 3931-3950, 1960.

Seppälä, A., Verronen, P. T., Clilverd, M. A., Randall, C. E., Tamminen, J., Sofieva, V., Backman, L., and Kyrölä, E.: Arctic and Antarctic polar winter $\mathrm{NO}_{\mathrm{x}}$ and energetic particle precipitation in 2002-2006, Geophys. Res. Lett., 34, 12810 , doi:10.1029/2007GL029733, 2007.

Shimazaki, T.: Minor Constituents in the Middle Atmosphere, no. 6 in Developments in Earth and Planetary Physics, D. Reidel Publishing Company, 1984.

Siskind, D. E., Bacmeister, J. T., Summers, M. E., and Russell, J. M.: Two-dimensional Model Calculations of Nitric Oxide Transport in the Middle Atmosphere and Comparison with Halogen Occultation Experiment Data, J. Geophys. Res., 102, 35273545, 1997.

Siskind, D. E., Barth, C. A., and Russell, J. M.: A climatology of nitric oxide in the mesosphere and thermosphere, Adv. Space Res., 21, 1353-1362, 1998.

Sylwester, J., Garcia, H. A., and Sylwester, B.: Quantitative interpretation of GOES soft X-ray measurements, Astron. Astrophys., 
293, 577-585, 1995.

Thomson, N. R., Rodger, C. J., and Dowden, R. L.: Ionosphere gives size of greatest solar flare, Geophys. Res. Lett., 31, 6803, doi:10.1029/2003GL019345, 2004.

Tobiska, W., Woods, T., Eparvier, F., Viereck, R., Floyd, L., Bouwer, D., Rottman, G., and White, O.: The SOLAR2000 empirical solar irradiance model and forecast tool, J. Atmos. SolarTerr. Phys., 62, 1233-1250, 2000.

Turunen, E.: High latitude D-region studies by incoherent scatter radar measurements, Ph.D. thesis, Sodankylä Geophysical Observatory, Tähteläntie 62, FIN-99600 Sodankylä, Finland, Sodankylä Geophysical Observatory Report, 52, 1993.

Turunen, E., Matveinen, H., Tolvanen, J., and Ranta, H.: D-Region Ion Chemistry Model, in: STEP Handbook of Ionospheric Models, edited by: Schunk, R. W., pp. 1-25, Scientific Committee on Solar-Terrestrial Physics, 1996.
Verronen, P. T.: Ionosphere-atmosphere interaction during solar proton events, Ph.D. thesis, Finnish Meteorological Institute, Helsinki, Finland, http://ethesis.helsinki.fi/, ISBN: 951-697-6506, 2006.

Verronen, P. T., Seppälä, A., Clilverd, M. A., Rodger, C. J., Kyrölä, E., Enell, C.-F., Ulich, T., and Turunen, E.: Diurnal variation of ozone depletion during the October-November 2003 solar proton event, J. Geophys. Res., 110, A09S32, doi:10.1029/2004JA010932, 2005.

Vitt, F. M., Cravens, T. E., and Jackman, C. H.: A two-dimensional model of thermospheric nitric oxide sources and their contributions to the middle atmospheric chemical balance, J. Atmos. Terr. Phys., 62, 653-667, 2000.

Woods, T. N., Eparvier, F. G., Solomon, S. C., Woodraska, D. L., and Bailey, S. M.: Early results from the TIMED solar EUV experiment, in: 4th (Virtual) Thermospheric/Ionospheric Geospheric Research (TIGER) Symposium, Fraunhofer Institute for Physical Measurement Techniques, 2002. 